\title{
Spontaneous ventilation in thoracoscopic thymectomy: breathing freely
}

\author{
Brian Cohen, M. Blair Marshall \\ Division of Thoracic Surgery, Department of Surgery, Medstar Georgetown University Hospital, Washington, DC, USA \\ Correspondence to: Dr. Brian Cohen, MD. Division of Thoracic Surgery, Department of Surgery, Medstar Georgetown University Hospital, \\ Washington, DC 20007, USA. Email: Brian.D.Cohen@gunet.georgetown.edu. \\ Comment on: Jiang L, Liu J, Gonzalez-Rivas D, et al. Thoracoscopic surgery for tracheal and carinal resection and reconstruction under spontaneous \\ ventilation. J Thorac Cardiovasc Surg 2018;155:2746-54.
}

Submitted Jul 12, 2018. Accepted for publication Sep 17, 2018.

doi: $10.21037 /$ jtd.2018.09.96

View this article at: http://dx.doi.org/10.21037/jtd.2018.09.96

Long Jiang and colleges, published a study in the April 2018 issue of "The Fournal of Thoracic and Cardiovascular Surgery" comparing the standard intubated video-assisted thoracic thymectomy (IVATT) to a spontaneous ventilation video-assisted thoracic thymectomy (SV-VATT) (1). They performed a retrospective analysis of consecutive patients, who had undergone a thymectomy after being diagnosed with myasthenia gravis (MG).

Patients in the IVATT group were induced with propofol (target plasma concentration $3 \mu \mathrm{g} / \mathrm{mL}$ ), sufentanil $(0.4 \mu \mathrm{g} / \mathrm{kg})$, and cisatracurium $(0.2 \mu \mathrm{g} / \mathrm{kg})$, and then were intubated with a double-lumen tube via laryngoscopy. Anesthesia was maintained with sevoflurane, propofol, and remifentanil. Alternatively, patients who had undergone SV-VATT were induced with propofol (with a targetplasma concentration to $2-3 \mu \mathrm{g} / \mathrm{mL}$ ) and sufentanil $(0.1-0.2 \mu \mathrm{g} / \mathrm{kg})$. No muscle relaxants were used. A thoracic epidural was then inserted, for an administration of $2 \%$ lidocaine and then $0.375 \%$ ropivacaine, as needed; with an anesthesia level reaching between T2 and T10. A laryngeal mask was then placed for oxygenation, and anesthesia was maintained with propofol and dexmedetomidine $(0.5-1.0 \mu \mathrm{g} / \mathrm{kg} / \mathrm{hr})$. Intraoperatively, under thoracoscopic guidance, $6 \mathrm{~mL}$ of lidocaine $2 \%$ was sprayed on the lung surface to reduce coughing. The goal spontaneous respiratory rate was set to $12-20$ breaths/minute. Both groups had maintained a BIS within 40-60.

After patients were appropriately anesthetized, surgical management proceeded in the same manner in both groups. After the operation, patients in the IVATT group were extubated, as was clinically appropriate, and patients undergoing SVATT, had their epidural catheters removed in the operating room. All patients were sent to recover in the post-anesthesia care unit, unless they had required continued intubation, in which case, they were sent to the intensive care unit. Patients were monitored for post-operative complications, pulmonary complications (infection, atelectasis), myasthenic crisis (MC), sore throats, and pain. It was also noted whether or not patients required a conversion to intubation, or experienced delayed extubation.

Post-operative patients in the IVATT group experienced more complications, including sore throats, air leaks, and pulmonary infections. One patient in the SV-VATT group had required a conversion to intubation along with a thoracotomy, this was attributed to dense pleural adhesions. Those in the IVATT group experienced more instances of MC, 14 patients (20.6\%) vs. 1 patient (2.8\%) in the SV-VATT group. Eighteen patients in the IVATT group (26.5\%) also experienced delayed extubation, versus 1 patient in the SV-VATT group (2.8\%). Length of hospital stay was longer for IVATT patients at $8.8 \pm 4.7 \mathrm{vs}$. $6.8 \pm 2.7$ days, $\mathrm{P}=0.02$.

Due to the non-randomized selection of patients into each group, the authors then matched patients according to a propensity score, which used variables such as: age, sex, body mass index, smoking status, comorbidity, pulmonary function tests, preoperative medication, and their clinical severity, according to the Myasthenia Gravis Foundation of America clinical classification scheme. Of the original 
36 and 68 patients who had undergone SV-VATT and IVATT, 27 were included in each group for analysis after a propensity score matching. The matched patients then continued to show no differences in surgical duration, mean lowest $\mathrm{SpO} 2$, or urine output. SV-VATT patients continued to show higher mean peak EtCO2, while IVATT patients experienced more complications. MC occurred in 3 patients who underwent IVATT (11.1\%) vs. 0 SV-VATT patients and 6 IVATT patients $(22.2 \%)$ required intubation $>1$-day vs. 0 SV-VATT patients. Post-operative pain was also lower and average length of hospitalization was shorter in the SVVATT group.

Since the first case reports describing thymectomy in patients who were diagnosed with MG by Blalock et al. $(2,3)$ to the randomized controlled trial by Wolfe et al. had favorably compared thymectomy plus prednisone to prednisone alone (4), much effort has gone into investigating the safest way to treat this patient population. While these studies had used the trans-sternal approach as the accepted standard, the use of video-assisted thoracoscopic (VATS) techniques have emerged as having comparable clinical outcomes, with decreased complications, improved pain, and shorter hospital stays $(5,6)$.

Despite the proven benefits of a VATS thymectomy over medical treatment alone, patients with MG still present a unique challenge to surgeons and anesthesiologists, with surgery acting as an inciting factor that could send these patients into respiratory failure (7). In an effort to minimize the risk posed by anesthesia in MG patients, Della Rocca et al. compared anesthetic techniques without neuromuscular blockades during trans-sternal thymectomy, (instead, using propofol or sevoflurane) (8). They showed these regimens to not only allow for adequate intubating conditions, but also early extubation in the operating room. Similar results were achieved by Gritti et al. in patients undergoing a VATS thymectomy (9).

Although the authors were able to show a lower incidence of $\mathrm{MC}$, and fewer patients experienced prolonged intubation, by maintaining spontaneous ventilation, this is likely not attributable to the IVATT versus SVVATT technique. The use of an invasive intubation was not the only variable between the groups, but likely the most significant. It is unclear why the authors chose to use paralytics in patients who were undergoing IVATT, as this is not necessary, and clearly has significant side effects in myasthenic patients. One could argue that the use of a paralytic alone, can explain the most significant complications in the IVATT group. Calling into question the validity of the comparison in this study. However, despite the aforementioned flaws, this work demonstrates that the technique of SV-VATT for thymectomy in myasthenic patients, is feasible and appears to be safe. Longer term follow-ups of these minimally invasive techniques will be needed, to address the impact of these techniques on the remission of myasthenia.

\section{Acknowledgements}

None.

\section{Footnote}

Conflicts of Interest: The authors have no conflicts of interest to declare.

\section{References}

1. Jiang L, Depypere L, Rocco G, et al. Spontaneous ventilation thoracoscopic thymectomy without muscle relaxant for myasthenia gravis: Comparison with "standard" thoracoscopic thymectomy. J Thorac Cardiovasc Surg 2018;155:1882-9.e3.

2. Blalock A, Mason MF, Morgan HJ, et al. Myasthenia gravis and tumors of the thymic region: report of a case in which the tumor was removed. Ann Surg 1939;110:544-61.

3. Blalock A, McGehee HA, Ford FR, et al. The treatment of myasthenia gravis by removal of the thymus gland. JAMA 1941;117:1529.

4. Wolfe GI, Kaminski HJ, Aban IB, et al. Randomized Trial of Thymectomy in Myasthenia Gravis. N Engl J Med 2016;375:511-22.

5. Friedant AJ, Handorf EA, Su S, et al. Minimally Invasive versus Open Thymectomy for Thymic Malignancies: Systematic Review and Meta-Analysis. J Thorac Oncol 2016;11:30-8.

6. Hess NR, Sarkaria IS, Pennathur A, et al. Minimally invasive versus open thymectomy: a systematic review of surgical techniques, patient demographics, and perioperative outcomes. Ann Cardiothorac Surg 2016;5:1-9.

7. Gracey DR, Divertie MB, Howard FM Jr, et al. Postoperative respiratory care after transsternal thymectomy in myasthenia gravis. A 3-year experience in 53 patients. Chest 1984;86:67-71.

8. Della Rocca G, Coccia C, Diana L, et al. Propofol or sevoflurane anesthesia without muscle relaxants allow the 
early extubation of myasthenic patients. Can J Anaesth 2003;50:547-52.

9. Gritti P, Carrara B, Khotcholava M, et al. The use of desflurane or propofol in combination with remifentanil in myasthenic patients undergoing a video-assisted

Cite this article as: Cohen B, Marshall MB. Spontaneous ventilation in thoracoscopic thymectomy: breathing freely. J Thorac Dis 2018;10(Suppl 33):S3859-S3861. doi: 10.21037/ jtd.2018.09.96 thoracoscopic-extended thymectomy. Acta Anaesthesiol Scand 2009;53:380-9.

(English Language Editor: Jeremy Dean Chapnick, AME Publishing Company) 